\title{
Effects of Exposure to Genistein and Estradiol on Reproductive Development in Immature Male Mice Weaned from Dams Adapted to A Soy-based Commercial Diet
}

\author{
Eun-Yong JUNG ${ }^{1}$, Beom-Jun LEE ${ }^{1}$, Young Won YUN ${ }^{1}$, Jong-Koo KANG ${ }^{1)}$, In-Jeoung BAEK ${ }^{1}$, Jung Min-YON ${ }^{1}$, \\ Yoon-Bok LEE ${ }^{2)}$, Heon-Soo SOHN ${ }^{2}$, Jae-Yong LEE ${ }^{3)}$, Kang-Sung KIM ${ }^{4)}$, Wook-Joon YU ${ }^{5)}$, Jae Cheul DO ${ }^{6}$, \\ Young Cheul $\mathrm{KIM}^{7)}$ and Sang-Yoon $\mathrm{NAM}^{1) *}$ \\ ${ }^{1)}$ Department of Veterinary Medicine and Research Institute of Veterinary Medicine, Chungbuk National University, Cheongju, 361-763, \\ ${ }^{2)}$ Central Research Institute, Dr. Chung's Food Co., Ltd., Cheongju 360-290, ${ }^{3)}$ Department of Biochemistry, College of Medicine, Hallym \\ University, Chunchon 200-702, ${ }^{4}$ Department of Food Science and Nutrition, Yong-in University, Yongin 449-714, ${ }^{5}$ Satefy Research \\ Center, Kotric, Kimpo 415-871, ${ }^{6}$ Gyeongbuk Veterinary Service Laboratory, Daegu 702-210 and ${ }^{7)}$ Department of Public Health, \\ College of Natural Sciences, Keimyung University, Daegu 704-701, Korea
}

(Received 16 March 2004/Accepted 1 June 2004)

ABSTRACT. Genistein, a soybean-originated isoflavone, is widely consumed by humans for putative beneficial health effects but its estrogenic activity may adversely affect the development of male reproductive system. Twenty one-day-old ICR mice weaned from dams fed with a soybean-based diet throughout gestation and lactation were exposed by gavage to genistein $(2.5 \mathrm{mg} / \mathrm{kg} \mathrm{b}$.w./day) or $17 \beta$-estradiol $(7.5 \mu \mathrm{g} / \mathrm{kg}$ b.w./day) for five weeks. Corn oil was used as a negative control. The animals were fed with a casein-based AIN-76A diet throughout the experimental periods. There were no significant differences in body and organ weights of mice among experim ental groups. No significant differences in sperm counts and sperm motile characteristics were found between control and genistein groups. Treatment of $17 \beta$-estradiol caused a significant decrease in prostate weight and epididymal sperm counts compared to the control $(\mathrm{p}<0.05)$. The levels of phospholipid hydroxide glutathione peroxidase in the testis and prostate of mice exposed to genistein or $17 \beta$ estradiol were significantly higher than that of the control mice $(\mathrm{p}<0.05) .17 \beta$-estradiol treatment caused degeneration and apoptosis of germ cells in the testis, depletion and degeneration in the epididymal epithelium, and hyperplasia of mucosal fold region in the prostate of mice. Genistein treatment did not cause any lesion in the testis, epididymis, and prostate. These results suggest that dietary uptake of genistein during juvenile period may not affect male reproductive development and functions.

KEY WORDS: estradiol, genistein, phospholipid hydroxide glutathione peroxidase, sperm.

J. Vet. Med. Sci. 66(11): 1347-1354, 2004

Genistein (4',5,7-trihydroxy-isoflavone), the principal soy isoflavone, has been the subject of numerous studies in experimental animals and humans because of its possible beneficial and adverse health effects due to estrogenic activity [25]. Epidemiological studies have revealed that individuals who consume a traditional diet high in soy products have a low incidence of certain types of cancer, such as breast, prostate and colon cancer [1]. Diets high in soy contain multiple agents that may contribute to the effect. Nonetheless, much research attention has focused on the isoflavones, particularly genistein, as active compounds responsible for the beneficial effects of soy [4]. In the typical Asian diet, $1.5 \mathrm{mg} / \mathrm{kg} /$ day of genistein or other isoflavones may be ingested, whereas the typical western diet contains less than $0.2 \mathrm{mg} / \mathrm{kg} /$ day [6]. The health benefits of soy isoflavones may be due to the presence of estrogenicity and/or anti-estrogenicity and a variety of other biological activities such as inhibition of angiogenesis, cell proliferation, tyrosine kinase activity, free radical production, and steroid metabolizing enzymes [12, 15, 32].

Research assessing the potential adverse effects associated with isoflavone consumption is primarily directed toward defining any potential risk from exposure to a range

\footnotetext{
* Correspondence to: Nam, S.-Y., Department of Veterinary Anatomy, College of Veterinary Medicine, Chungbuk National University Cheongju 361-763, Korea.
}

of doses of isoflavones during different life stages. There has been considerable debate over the possible risks and/or benefits of isoflavone consumption during the sensitive stages of fetal and infant development, because of the weak estrogenic activity of genistein and other isoflavones [18, 29]. Early developmental exposure to estrogenic chemicals is known to cause reproductive tract abnormalities, decrease reproductive organ weights, and potentially compromise sperm production and sperm quality in experimental animals, wildlife, and humans $[5,7,26]$. These findings have raised concern over exposure to estrogenic isoflavonoids and other exogenous weak estrogens in our food and water supplies. Because of the widespread exposure of humans to significant doses of soy isoflavones at various stages of development, the data obtained from animal models can be evaluated for its relevance to human risk assessment more readily than is the case for the other endocrine active chemicals with limited human exposure.

There are many recent reports on effects of genistein on reproductive functions $[9,11,17,21]$. Several papers showed no adverse effects of genistein on animal reproductive systems at the human intake dose level [11, 12, 17, 19]. On the contrast, some showed adverse effects of genistein on reproductive function after puberty in animals [9, 21, 33]. The discrepancy in those results may be due to differences in critical time, duration and dose of exposure to genistein 
and/or use of animal species and strains.

The present study was carried out to evaluate whether genistein or $17 \beta$-estradiol causes adverse effects on reproductive system in immature male mice as exposed for 5 weeks from postnatal day (PND) 21 to 56 after weaning from dams fed with a soy-based Purina Chow diet. The animals were fed with a casein-based AIN 76A diet during the experimental period after weaning. Changes in the weight and histopathology of reproductive organs, sperm count and sperm motility, and levels of phospholipid hydroxide glutathione peroxidase (PHGPx) mRNA expression were investigated.

\section{MATERIALS AND METHODS}

Chemicals: Genistein (purity, >98\%), 17- $\beta$ estradiol, and corn oil were obtained from Sigma Chemical Co. (St. Louis, Mo, U.S.A.). Genistein was diluted with corn oil and mixed vigorously prior to its use. The other chemicals and reagents used in this study were also purchased from Sigma and were of the highest grade commercially available.

Laboratory animals: ICR mice were purchased from Biolink Inc. (Seoul, Korea) and housed in polycarbonate cages with wood chip bedding. Animal facilities were maintained under controlled conditions with temperature of $21 \pm 2{ }^{\circ} \mathrm{C}$, relative humidity of $50 \pm 10 \%$ and artificial illumination with a 12-hr light-dark cycle. All animals received humane care as outline by the "Guide for the care and use of animals" (Chungbuk National University Animal Care Committee according to NIH \#86-23). Animals were fed with a soy-based Purina Chow diet (Purina Korea, Seoul) during gestation and lactation before exposure to genistein. Three-week-old male mice (PND 21) after weaning from dams fed with the soy-based diet were randomly divided into 3 experimental groups (10 mice per group) comprising corn oil (control), genistein ( $2.5 \mathrm{mg} / \mathrm{kg}$ b.w.), and $17 \beta$-estra$\operatorname{diol}(7.5 \mu \mathrm{g} / \mathrm{kg}$ b.w.). The animals were orally administered daily with the test compounds for 5 weeks under a caseinbased AIN-76A diet (Harlan Teklad, Madison, WI, U.S.A.). Animals were sacrificed under anesthesia with ethyl ether and their reproductive organs including testis, epididymis, and prostate were removed and weighed.

Sperm counts in testis and cauda epididymis: Testicular parenchyma tissue was displaced in $12 \mathrm{~m} l$ distilled water at $4-6^{\circ} \mathrm{C}$. The tissue was homogenized at a low speed for $1.5-$ 2 min using a polytron homogenizer (Omni 5,000 International Co, Waterburg, CT, U.S.A.) and sonicated for $3 \mathrm{~min}$ at $4^{\circ} \mathrm{C}$. Cauda epididymis was chopped with a sharp scissor and homogenized with a low speed in $10 \mathrm{ml}$ distilled water for $1.5-2 \mathrm{~min}$ at $4-6^{\circ} \mathrm{C}$. The number of homogenizationresistant spermatids was enumerated using a hemocytometer.

Analysis of sperm kinematics: The working medium for mouse sperm kinematics was a modified Tyrode's solution [31], as described by Holloway et al. [16]. It was equilibrated overnight to a $\mathrm{pH}$ of $7.35 \pm 0.5$ in a $5 \% \mathrm{CO}_{2}$ incubator at $37^{\circ} \mathrm{C}$. For sperm motility assessment, the medium was modified with addition of $0.4 \%$ bovine serum albumin (BSA) and equilibrated to a $\mathrm{pH}$ of $7.35 \pm 0.5$. Each testis and ex-current duct was immediately recovered by a midline incision. Caudal epididymis and vas deferens were dispersed, dissected free of the epididymis and surrounding fat, and washed in media. The epididymis was placed in $3 \mathrm{ml}$ of the modified Tyrode's medium supplemented with $0.4 \%$ BSA in a $35 \mathrm{~mm}$ plastic petri dish at $37^{\circ} \mathrm{C}$. After the tissue was removed, sperm suspension was collected, gently mixed, and kept at $37^{\circ} \mathrm{C}$ in $5 \% \mathrm{CO}_{2}$ in air. Aliquots of the sperm suspension were diluted with fresh medium to an adequate concentration. The aliquots of $30 \mu l$ were placed in pre-warmed slide chambers with a depth of $20 \mu \mathrm{m}$. The slide chambers were transferred to the heated plate of an inverted phase-contrast microscope (Olympus IX 70, Tokyo, Japan). PH2 condenser and 4X PH1 object lenses were used to produce pseudo-dark-field views. Computerassisted sperm motility analysis (CASA) was performed using a sperm image analysis system (SIAS, Medical supply Co., Seoul, Korea). Images were recorded in real time over extended periods. For each slide, the tracks of sperm in 10 fields were recorded for approximately 2-3 min [35]. Centroids were used for estimation of the motion endpoint, which includes motility (number of sperm exceeding threshold minimum velocity/total number of sperm), curvilinear velocity (VCL; mean frame-to-frame velocity), straight-line velocity (VSL: velocity between centroids in first and last frame tracked), average path velocity (VAP: velocity obtained from smoothing the original path), hyper-activated sperm (HYP), beat cross frequency (BCF: frequency of centroid crossing average trajectory), mean angular displacement (MAD: time-average of absolute values of the instantaneous turning angle of the sperm head along its curvilinear trajectory), lateral head displacement (ALH: displacement of the centroid from a computer-calculated average trajectory). Linearity (LIN; [VSL/VCL]x100), straightness (STR: [VSL/VAP]x100), and dance (DNC: VCLXALH) were calculated with the above parameters. These parameters have been modeled and refined mathematically to describe the motion of each spermatozoon as it travels through a microscopic dark field [3].

Histopathological evaluation: Body weights (every week) and sex organ weights including testis, epididymis, and prostate were measured. The testis, epididymis, and prostate were fixed in Bouin's fixative and washed with saturated lithium carbonate in $70 \%$ ethyl alcohol to remove excess of the fixative. After normal tissue processing using an automatic tissue processor (Shandon Hypercenter XP, Houston, TX, U.S.A.) and an embedding center (Leica, Solms, Germany), the tissues were stained with hematoxylin and eosin (H\&E) and examined microscopically.

Total RNA isolation and reverse transcription-polymerase chain reaction $(R T-P C R)$ : Total RNA was extracted from testis, epididymis, and prostate using the TRIzol reagent (Life Technologies, Gaithersburg, MD, U.S.A.), according to the manufacturer's instruction [22]. The RNA pellet obtained in the final step was dissolved in $50 \mu \mathrm{l}$ of 
sterile diethylpyrocarbonate (DEPC)-treated water and its concentration was determined by a UV spectrophotometer at $260 \mathrm{~nm}$. RNA was kept in DEPC-treated water at $-70^{\circ} \mathrm{C}$ until its use. Reverse transcription of mRNA and amplification of cDNA were performed using a Pelter thermal cycler (MJ Research Inc. Waltham, MA, U.S.A.). Total RNA (1.0 $\mu \mathrm{g}$ ) was synthesized by using the first strand cDNA synthesis kit (Boehringer Mannheim, Mannheim, Germany) following the manufacturer's instruction. The PCR mixture was made as the followings: $0.15 \mu l$ of TaqGold DNA polymerase (Perkin Elmer; Boston, MA, U.S.A.), $1.0 \mu l$ of sense primer for PHGPx (5'-ATGCA CGAAT TC TCA GCCAA G-3'), $1.0 \mu l$ of antisense primer (5'-GGCAG GTCCT TCTCT AT-3'), $2.5 \mu l$ of dNTPs, $2.5 \mu l$ of 10-strength PCR buffer containing $1.5 \mathrm{mM} \mathrm{MgCl}{ }_{2}$, and $1 \mu \mathrm{l}$ of template cDNA in $16.85 \mu \mathrm{l}$ of ultra-distilled water. PCR amplification was carried out in the thermal cycler using a protocol of initial denaturing step at $95^{\circ} \mathrm{C}$ for $10 \mathrm{~min}$; then 35 cycles at $95^{\circ} \mathrm{C}$ for $1 \mathrm{~min}$ (denaturing), at $55^{\circ} \mathrm{C}$ for 1 min (annearing), and at $72^{\circ} \mathrm{C}$ for $1.5 \mathrm{~min}$ (extension); and a further extention at $72^{\circ} \mathrm{C}$ for $10 \mathrm{~min}$. The PCR products were run on a $2 \%$ agarose gel in Tris-borate-EDTA buffer. Every sample was also tested for RNA integrity by using GAPDH (intrinsic control) primers: sense primer (5'-AACGG ATTTG GTCGT ATTGG-3'), antisense primer (5'-AGCCT TCTCC ATGGT GGTGA AGAC-3'). Expected PCR products sizes of PHGPx and GAPDH were 462 and 302 bp, respectively. The relative absorbance of specific mRNA was normalized to the relative absorbance of GAPDH mRNA.

Statistical analysis: Data were analyzed using the SAS program for ANOVA. The significance of difference in the mean between treatment groups and control group was evaluated statistically by least significant difference (LSD) at the level of $\mathrm{p}<0.05$ and $\mathrm{p}<0.01$.

\section{RESULTS}

Body and organ weights: Changes in body weights are shown in Fig. 1. There were no significant differences in body weight between control and genistein-treated groups. However, estradiol treatment showed a slightly decreased trend in body weight compared to genistein group or control group (Fig. 1). Relative organ weights for each group are shown in Fig. 2. There were no significant differences in the relative weights of epididymis and testis among experimental groups (Fig. 2). However, estradiol treatment significantly decreased the relative prostate weight compared to the control $(\mathrm{p}<0.05)$.

Sperm count and sperm motility: Exposure to genistein for 5 weeks from PND 21 to PND 56 did not affect sperm counts in the epididymis and testis (Fig. 3). Estradiol treatment caused a significant decrease in sperm counts in the epididymis by about $40 \%$ compared to the control ( $p<0.05)$. Changes in sperm motile characteristic are shown in Fig. 4. The sperm motile characteristics including MOT, VCL, VSL, VAP, HYP, BCF, MAD, and ALH were slightly

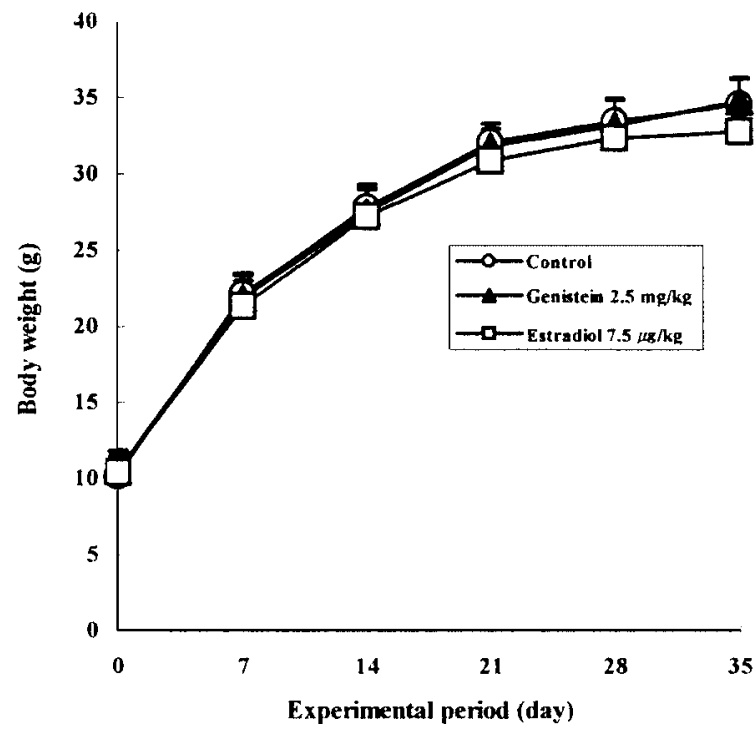

Fig. 1. Average body weight changes in male ICR mice exposed to genistein and $17 \beta$-estradiol for 5 weeks from PND 21 to 56 . Values represent mean \pm SD $(n=10)$. * $\mathrm{p}<0.05$; compared to the control.

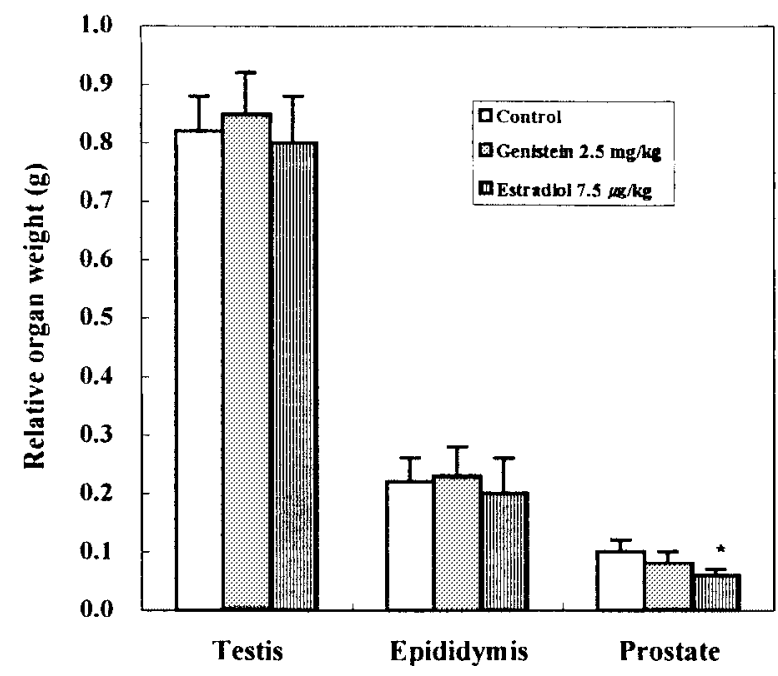

Fig. 2. Relative organ weights in male ICR mice exposed to genistein and $17 \beta$-estradiol for 5 weeks from PND 21 to 56 . Values represent mean \pm SD $(n=10)$. $* \mathrm{p}<0.05$; compared to the control.

higher in the genistein-exposed group than in the control group (Fig. 4). Meanwhile, the sperm motile characteristics were slightly lower in the estradiol-treated group than in the genistein-exposed group or the control group (Fig. 4).

PHGPX mRNA expression: The level of PHGPx mRNA expression in the epididymis of mice exposed to genistein was significantly $(\mathrm{p}<0.05)$ higher than that of the control (Fig. 5). There were no significant differences in the levels of PHGPx expression in the testis and prostate among the experimental groups (Fig. 5). 


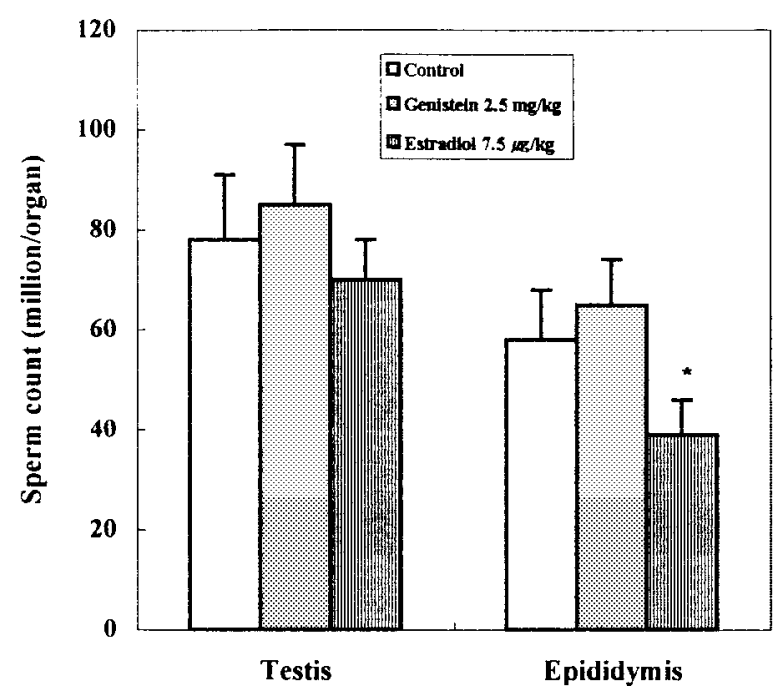

Fig. 3. Epididymal and testicular sperm counts in male ICR mice exposed to genistein and $17 \beta$-estradiol for 5 weeks from PND 21 to 56. Sperm counts are indicated as millions/one epididymis or testis. Values represent mean $\pm \mathrm{SD}(\mathrm{n}=10)$. ${ }^{*} \mathrm{p}<0.05$; compared to the control.

Histopathological findings: Estradiol treatment caused an inadequate preservation of seminiferous tubules in the subcapsular area with cytoplasmic rarefaction and it also separated spermatogenic cells from the epithelium in the testis (Fig. 6C). Depletion and degeneration of the epithelium were found in the epididymis treated with estradiol (Fig. 7C). Estradiol treatment also caused hyperplasia of epithelial cells in the prostate (Fig. 8C). Genistein treatment caused no pathological lesions in the testis, epididymis, and prostate (Figs. 6A, 7A, \& 8A).

\section{DISCUSSION}

An early exposure to exogenous estrogenic chemicals can disrupt male reproductive development and impair fertility at later stages of life $[5,7,26]$. Many rodent diets contain compounds such as soy isoflavones known to have estrogenic properties [8]. The dietary background of phytoestrogens may modulate some responses to environmental estrogens when these compounds are tested in a rodent bioassay [28]. In the present study, maternal exposure to genistein using a soybean-based diet during gestation and lactation was carried out and then F1 offspring (PND 21PND 56) exposed to genistein were fed with a casein-based open formula (AIN-76A) purified diet with non-detectable levels of estrogenic isoflavones throughout the experiment [30]. Our study clearly has shown that the exposure to genistein by oral gavage during pubertal development did not affect male reproductive functions including sperm counts and sperm quality. The exposure to genistein did not cause any change in relative weights and histopathology of the testis, epididymis, and prostate. On the contrast, treatment of estradiol, as a positive control, caused severe
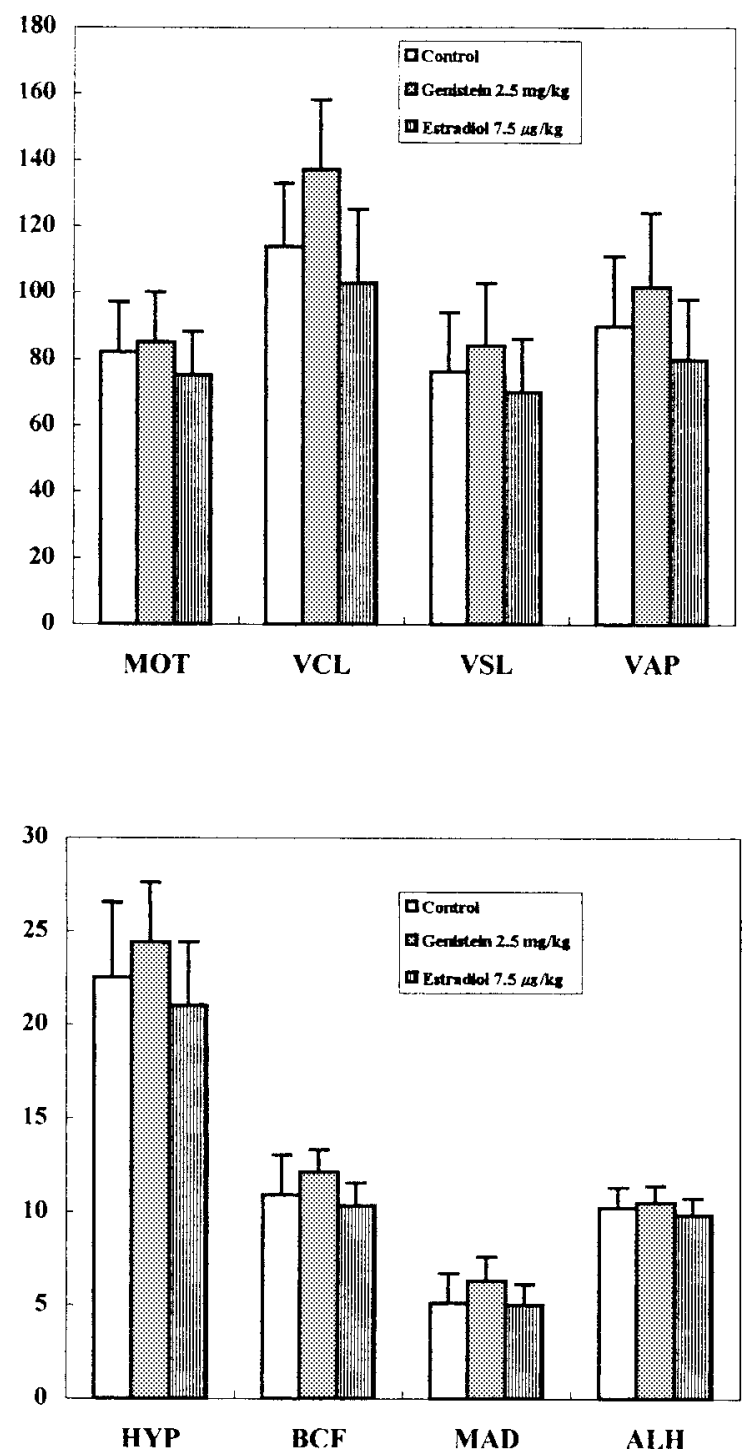

Fig. 4. Sperm motion characteristics in male ICR mice exposed to genistein and $17 \beta$-estradiol for 5 weeks from PND 21 to 56. Motility: MOT (\%), Curvilinear Velocity: VCL $(\mu \mathrm{m} / \mathrm{s})$, Straight-Line Velocity: VSL $(\mu \mathrm{m} / \mathrm{s})$, AveragePath Velocity: VAP $(\mu \mathrm{m} / \mathrm{s})$, Hyperactivated Sperm: HYP (\%), Beat-Cross Frequency: BCF (Hz), Mean Angular Displacement: MAD (degree), Amplitude of Lateral Head Displacement: ALH $(\mu \mathrm{m})$. Values represent mean \pm SD $(\mathrm{n}=10) .{ }^{*} \mathrm{p}<0.05$; compared to the control.

impairment of the reproductive system in mice.

The effects of genistein on reproductive development in animals are still controversial. Several reports showed that maternal exposure to genistein at a dose comparable to human intake during gestation and/or lactation has no adverse effects on reproductive organs weight and gametogenic function in F1 male offspring as well as fertility and early embryonic development $[11,17,24]$. Neonatal exposure to genistein at $40 \mathrm{mg} / \mathrm{kg} / \mathrm{day}$ during birth and PND 21 


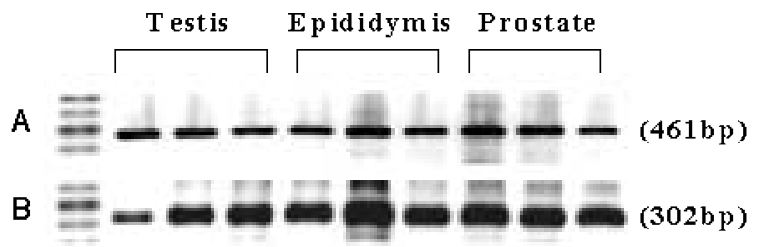

$\begin{array}{lllllllll}1 & 2 & 3 & 1 & 2 & 3 & 1 & 2 & 3\end{array}$

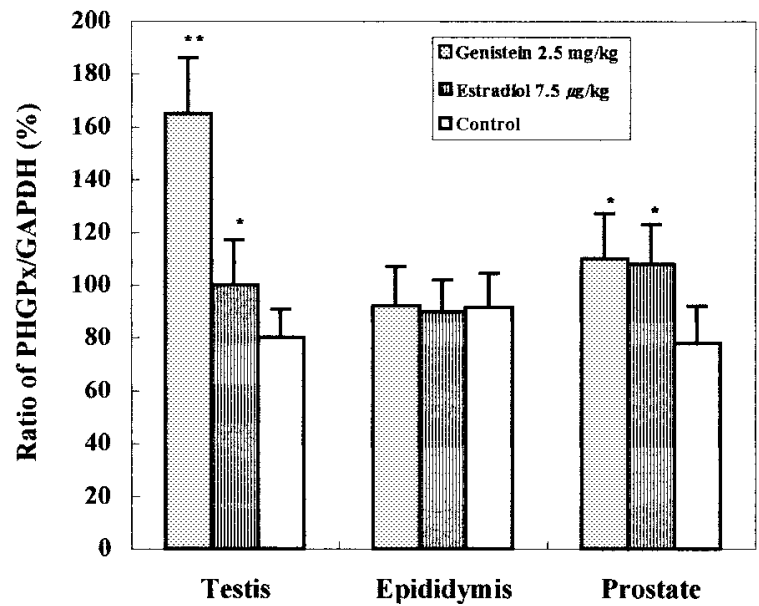

Fig. 5. PHGPx mRNA expression patterns in male ICR mice exposed to genistein and $17 \beta$-estradiol for 5 weeks from PND 21 to 56 . Genistein $2.5 \mathrm{mg} / \mathrm{kg}$ (1), $17 \beta$-estradiol $7.5 \mu \mathrm{g} / \mathrm{kg}$ (2), Control (3). cDNAs of testis, epididymis, and prostate loaded an $2.0 \%$ agrose gel. A) A representative expression of PHGPx mRNA and B) the corresponding GAPDH mRNA. The ratios of PHGPx to GAPDH bands were calculated.

impaired the development of female reproductive organs but not development of male reproductive organs in offspring [19]. Fritz et al. [12] reported that dietary exposure to genistein (250 and 1,000 ppm) from PND 21 to PND 35 did not adversely affect testicular development but dietary exposure to diethylstilbesterol $(75 \mu \mathrm{g} / \mathrm{kg}$ diet $)$ severely disturbed testicular development in rats. Although there were some differences in timing, duration and/or dose of exposure to genistein and use of animal species and strains, their reports clearly showed no adverse effects of genistein on the reproductive development in male animals. Our results are consistent with their reports in that body weight, organ weights, and sperm counts were not affected by exposure to genistein during pubertal development.

Meanwhile, adverse effects of genistein on reproductive system have been also reported $[9,19,21,27]$. Nagao et al. [21] reported that oral exposure to genistein at the doses of $12.5,25,50$, and $100 \mathrm{mg} / \mathrm{kg}$ b.w. on PND 1 through 5 after puberty decreased body weights in female and male rats. Estrous cycle and fertility in female rats were also affected by the genistein treatment at the high dose of $100 \mathrm{mg} / \mathrm{kg} / \mathrm{day}$ [21]. Delclos et al. [9] reported that dietary exposure of genistein at 1,250 ppm to pregnant and lactating dams starting on gestation day 7 affected function and histology of reproductive organs in both female and male pups. Wis-
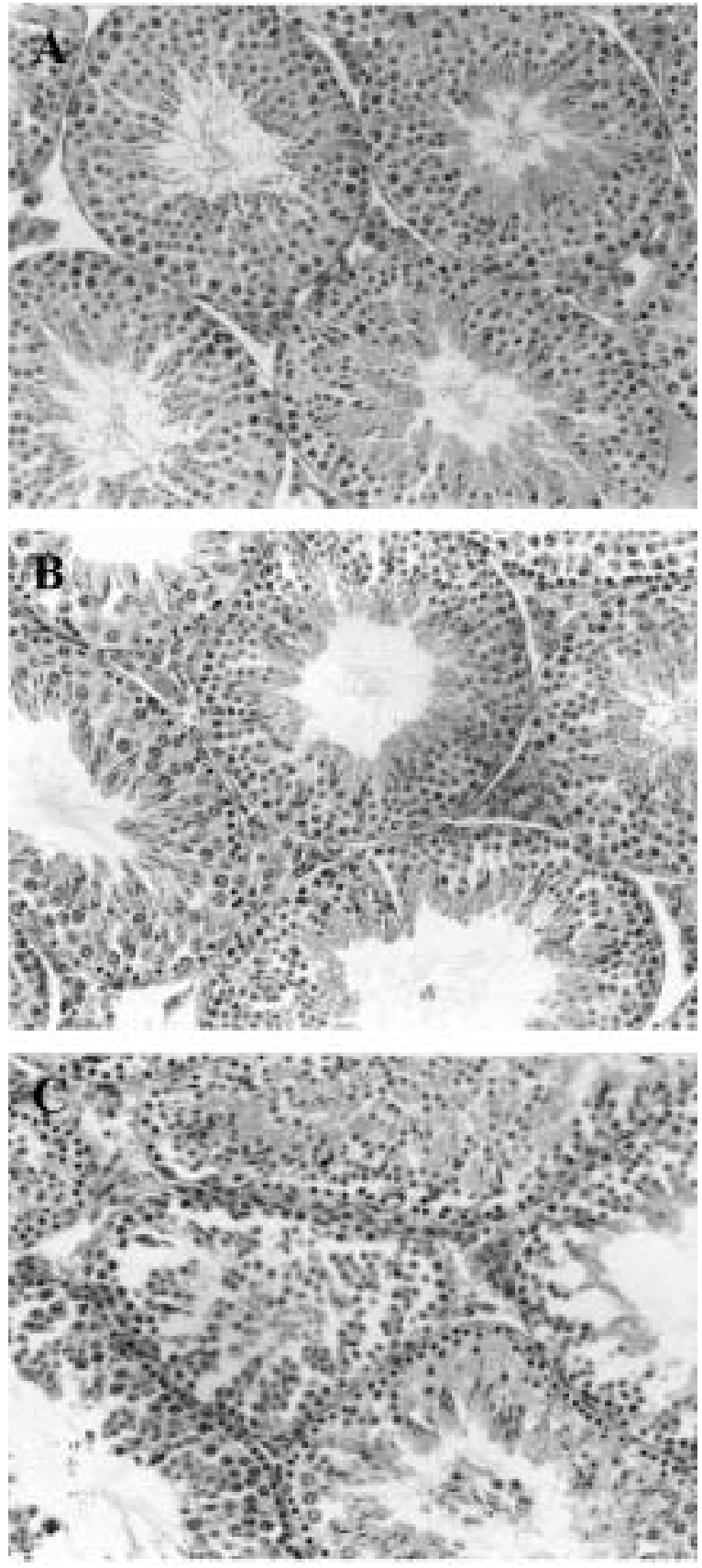

Fig. 6. Histopathology of testis in male ICR mice exposed to genistein and $17 \beta$-estradiol for 5 weeks from PND 21 to 56 . (A): Control, (B): Genistein ( $2.5 \mathrm{mg} / \mathrm{kg} /$ day) - No pathological lesions are found, (C): $17 \beta$-estradiol $(7.5 \mu \mathrm{g} / \mathrm{kg} / \mathrm{day})$-Inadequate preservation of seminiferous tubles in subcapsular area with cytoplasmic rarefaction and separation of spermatogenic cells from the epithelium. $\mathrm{H} \& \mathrm{E}, \times 100$.

niewski et al. [19] also reported that perinatal exposure to genistein resulted in transient and lasting alterations in masculinization of the reproductive system in male rats. Strauss et al. [27] reported that in adult male mice, genistein 

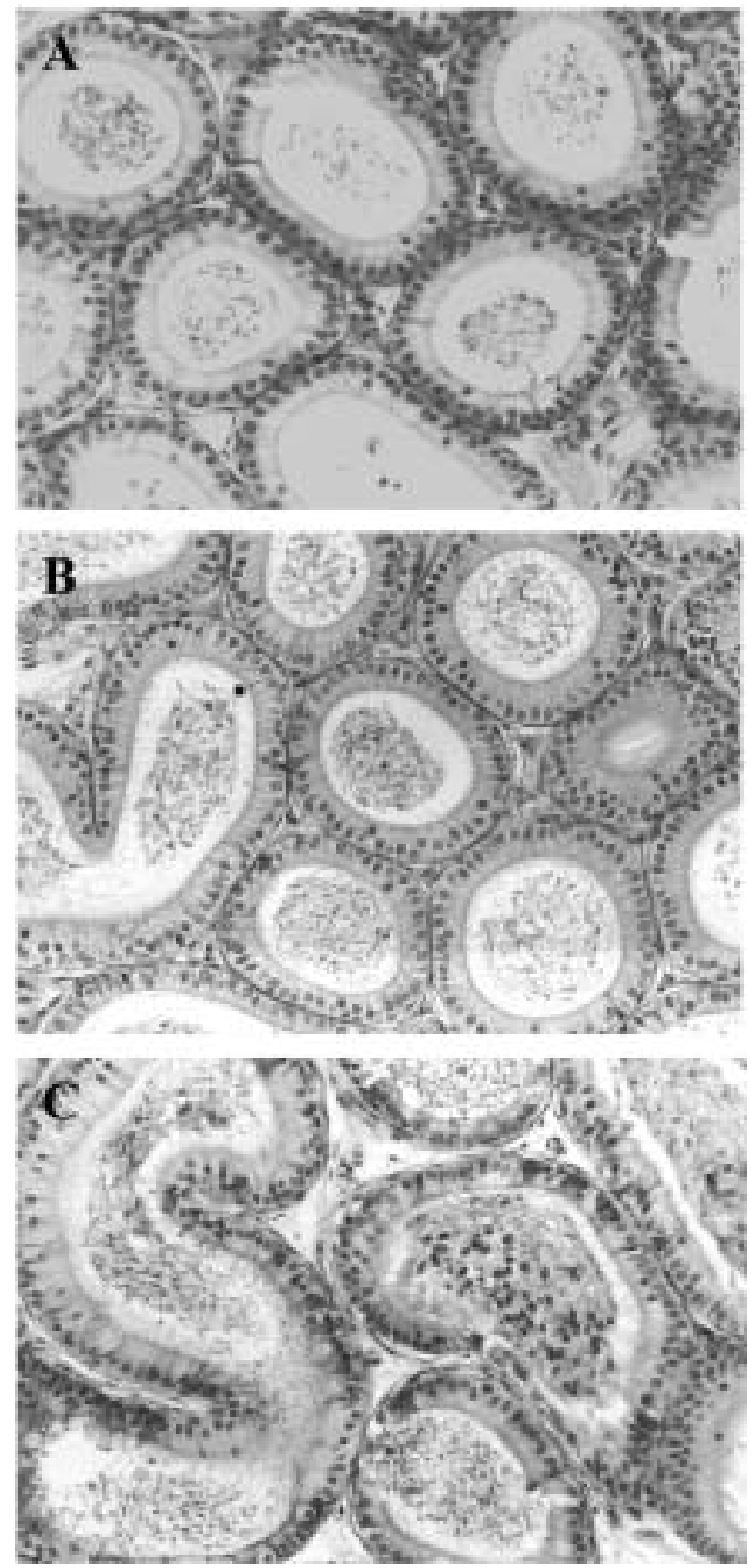

Fig. 7. Histopathology of epididymis in male ICR mice exposed to genistein and $17 \beta$-estradiol for 5 weeks from PND 21 to 56. (A): Control, (B): Genistein $(2.5 \mathrm{mg} / \mathrm{kg} / \mathrm{day})-\mathrm{No}$ lesions are found, (C): $17 \beta$-estradiol $(7.5 \mu \mathrm{g} / \mathrm{kg} / \mathrm{day})$-Depletion and degeneration of epithelium and presence of abnormal spermatogenic cells in epididymal ducts. $\mathrm{H} \& \mathrm{E}, \times 100$.

induced typical estrogenic effects at the doses comparable to those present in soy-based diets, while in neonatal animals, considerably higher doses were required to show estrogenlike activity. These adverse effects may be due to the ability of genistein to cross placenta and to reach fetal brain from maternal serum genistein levels that are relevant to those observed in humans [10]. These reports suggest that dietary
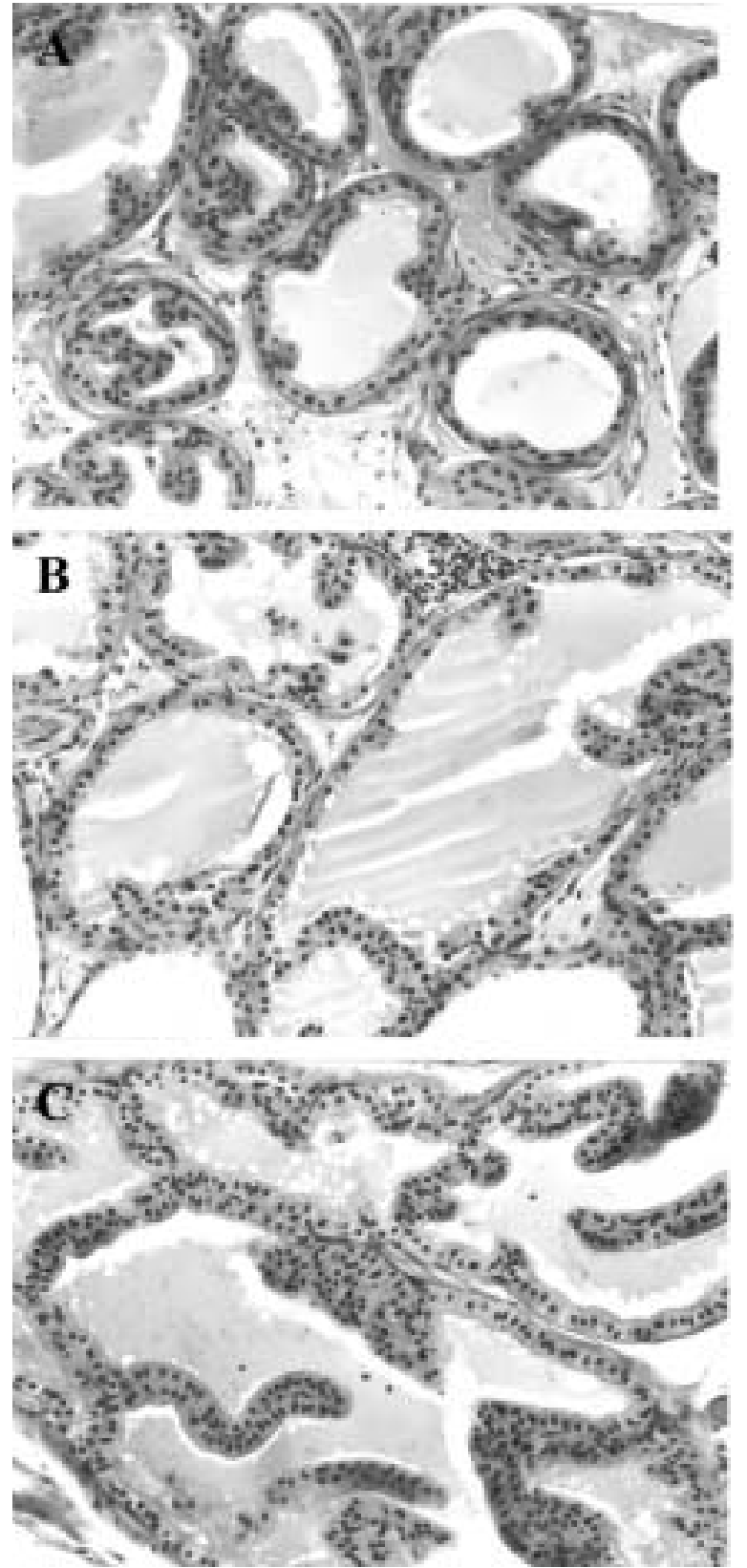

Fig. 8. Histopathology of prostate in male ICR mice exposed to genistein and $17 \beta$-estradiol for 5 weeks from PND 21 to 56 . (A): Control, (B): Genistein $(2.5 \mathrm{mg} / \mathrm{kg} / \mathrm{day})$-No lesions are found, (C): $17 \beta$-estradiol $(7.5 \mu \mathrm{g} / \mathrm{kg} /$ day $)$-Hyperplasia of mucosal fold region. $\mathrm{H} \& \mathrm{E}, \times 100$.

genistein ranges available in humans produce the effects in multiple estrogen-sensitive tissues in males and females that are generally consistent with its estrogenic activity [9]. In the present study, estradiol treatment induced severe impairment in male reproductive system. Although the exposure to genistein induced no histopathological changes in the testis, epididymis, and prostate of mice, the estrogenic activity 
of genistein may not be excluded. Our study has also shown that genistein or estradiol exposure significantly increased PHGPx expression in the testis and prostate, probably due to an estrogenic activity. Nam et al. [22] reported that estradiol increased PHGPx expression in the testis and prostate of rats, suggesting that estrogen might regulate PHGPX transcription in male reproductive organs [22]. However, the increased expression of PHGPx may also be in compensation for the damage by the estrogenic compound [22].

Sperm motility is an important factor to maintain fertilization. Genistein inhibits the induction of acrosomal exocytosis and binding of spermatozoa to the zona pellucida ( $\mathrm{ZP}$ ) [34]. ZP-induced acrosomal exocytosis in cat spermatozoa is regulated via a tyrosine kinase-dependent pathway, suggesting that a defect in the signaling pathway may cause a compromised sperm dysfunction [23]. Genistein, an inhibitor of protein phosphorylation and dephosphorylation, may play a regulatory role in mediating mouse sperm capacitation [13]. A previous in vivo report showed that genistein inhibits tyrosine phosphorylation of sperm tail protein and blocks capacitation and subsequently sperm hyperactivity [20]. The in vivo effect may be associated with a decrease in fertilizing ability of sperm. However, many reports have shown that genistein has no effects on sperm motility parameters [14]. In the present study, the exposure to genistein slightly increased sperm motile characteristics compared to the control. Fielden et al. [11] reported that exposure to genistein at a dose of $10 \mathrm{mg} / \mathrm{kg} / \mathrm{day}$ significantly increased the in vitro fertilizing ability of epididymal sperm by $17 \%$.

Although several reports indicate adverse effects of genistein on the reproductive system, our results suggest that daily intake of genistein has no observable detrimental effects on male reproductive development. The present study extend our knowledge of the effects of early genistein exposure on male development and may have implications for human health in terms of potential relationships of endocrine disrupters and urogenital abnormalities thought to be increasing in incidence in boys and men.

ACKNOWLEDGMENTS. This work was supported by a grant from the Korea Health 20 R\&D Project, Ministry of Health and Welfare, Republic of Korea (oo-PJ1-PG4PT04-0003).

\section{REFERENCES}

1. Adlercreutz, H. 1990. Western diet and Western diseases: some hormonal and biochemical mechanisms and associations. Scand. J. Clin. Lab. Invest. (Suppl.) 50: 3-23.

2. Bouker, K. B. and Hilakivi-Clarke, L. 2000. Genistein: does it prevent or promote breast cancer? Environ. Health Perspect. 108: 701-708.

3. Cancel, A. M., Lobdell, D., Mendola, P. and Perreault, S. D. 2000. Objective evaluation of hyperactivated motility in rat spermatozoa using computer-assisted sperm analysis. Hum. Reprod. 15: 1322-1328.

4. Chen, W. F., Huang, M. H., Tzang, C. H., Yang, M. and Wong,
M. S. 2003. Inhibitory actions of genistein in human breast cancer (MCF-7) cells. Biochim. Biophys. Acta 1638: 187-196.

5. Colburn, T., Vom, S. F. and Soto, A. M. 1993. Developmental effects of endocrine-disrupting chemicals in wildlife and humans. Environ. Health Perspect. 101: 378-384.

6. Coward, L., Barnes, N. C., Setchell, K. D. R. and Barnes, S. 1993. Genistein and daidzein, and their-glucoside conjugate: anti-tumer isoflavones in soybean foods from American and Asian diets. J. Agric. Food Chem. 41: 1961-1967.

7. David, J., Hendelsmen, S., Wishart, A. and Conway, J. 2000. Oestradiol enhances testosterone-induced suppression of human spermatogenesis. Hum. Reprod. 15: 672- 679.

8. Degen, G. H., Janning, P., Diel, P., Michna, H. and Bolt, H. M. 2002. Transplacental transfer of the phytoestrogen daidzein in DA/Han rats. Arch. Toxicol. 76: 23-29.

9. Delclos, K. B., Bucci, T. J., Lomax, L. G., Latendresse, J. R., Warbritton, A., Weis, C. C. and Newbold, R. R. 2001. Effects of dietary genistein exposure during development on male and female CD (Sprague-Dawley) rats. Reprod. Toxicol. 15: 647663.

10. Doerge, D. R., Churchwell, M. I., Chang, H. C., Newbold, R. R. and Delclos, K. B. 2001. Placental transfer of the soy isoflavone genistein following dietary and gavage administration to Sprague Dawley rats. Reprod. Toxicol. 15: 105-110.

11. Fielden, M. R., Samy, S. M., Chou, K. C. and Zacharewski, T. R. 2003. Effect of human dietary exposure levels of genistein during gestation and lactation on long-term reproductive development and sperm quality in mice. Food Chem. Toxicol. 41: 447-454.

12. Fritz, W. A., Cotroneo, M. S., Wang, J., Eltoum, I. E. and Lamartiniere, C. A. 2003. Dietary diethylstilbestrol but not genistein adversely affects rat testicular development. J. Nutr. 133: $2287-2293$

13. Furuya, S., Endo, Y., Oba, M., Nozawa, S. and Suzuki, S. 1992. Effects of modulators of protein kinases and phosphatases on mouse sperm capacitation. J. Assist. Reprod. Genet. 9: 391-399.

14. Hinsch, K. D., Aires, V., Hagele, W. and Hinsch, E. 2000. In vitro tests for essential sperm functions using the phyto-oestrogen genistein as a test substance. Andrologia 32: 225-231.

15. Hodek, P., Trefil, P. and Stiborova, M. 2002. Flavonoidspotent and versatile biologically active compounds interacting with cytochromes P450. Chem. Biol. Interact. 139: 1-21.

16. Holloway, A. J., Moore, H. D. M. and Foster, P. M. D. 1990. The use of in vitro fertilization to detect reductions in the fertility of male rats exposed to 1,3-dinitrobenzene. Fundam. Appl. Toxicol. 14: 113-122.

17. Kang, K. S., Che, J. H. and Lee, Y. S. 2002. Lack of adverse effects in the $\mathrm{F} 1$ offspring maternally exposed to genistein at human intake dose level. Food Chem. Toxicol. 40: 43-51.

18. Lamartiniere, C. A., Murrill, W. B., Manzolillo, P. A., Zhang, J. X., Barnes, S., Zhang, X., Wei, H. and Brown, N. M. 1998. Genistein alters the ontogeny of mammary gland development and protects against chemically-induced mammary cancer in rats. Proc. Soc. Exp. Biol. Med. 217: 358-364.

19. Lewis, R. W., Brooks, N., Milburn, G. M., Soames, A., Stone, S., Hall, M. and Ashby, J. 2003. The effects of the phytoestrogen genistein on the postnatal development of the rat. Toxicol. Sci. 71: 74-83.

20. Mahony, M. C. and Gwathmey, T. 1999. Protein tyrosine phosphorylation during hyperactivated motility of cynomolgus monkey (Macaca fascicularis) spermatozoa. Biol. Reprod. 60: 1239-1243. 
21. Nagao, T., Yoshimura, S., Saito, Y., Nakagomi, M., Usumi, K. and Ono, H. 2001. Reproductive effects in male and female rats of neonatal exposure to genistein. Reprod. Toxicol. 15: 399-411.

22. Nam, S. Y., Baek, I. J., Lee, B. J., In, C. H., Jung, E. Y., Yon, J. M., Ahn, B. W., Kang, J. K., Yu, W. J. and Yun, Y. W. 2003. Effects of $17 \beta$-estradiol and tamoxifen on the selenoprotein phospholipids hydroperoxide glutathione peroxidase (PHGPx) mRNA expression in male reproductive organs of rats. $J$. Reprod. Dev. 49: 389-396.

23. Pukazhenthi, B. S., Wildt, D. E., Ottinger, M. A. and Howard, J. 1998. Inhibition of domestic cat spermatozoa acrosome reaction and zona pellucida penetration by tyrosine kinase inhibitors. Mol. Reprod. Dev. 49: 48-57.

24. Roberts, D., Veeramachaneni, D. N., Schlaff, W. D. and Awoniyi, C. A. 2000. Effects of chronic dietary exposure to genistein, a phytoestrogen, during various stages of development on reproductive hormones and spermatogenesis in rats. Endocrine 13: 281-286.

25. Setchell, K. D. 1998. Phytoestrogens: the biochemistry, physiology, and implications for human health of soy isoflavones. Am. J. Clin. Nutr. 68: 1333s-1346s.

26. Spearow, J. L., Doemeny, P. and Sera, R. 1999. Genetic variation susceptibility to endocrine disruption by estrogen in mice. Science 285: 1259-1261.

27. Strauss, L., Makela, S., Joshi, S., Huhtaniemi, I. and Santti, R. 1998. Genistein exerts estrogen-like effects in male mouse reproductive tract. Mol. Cell Endocrinol. 144: 83-93.

28. Stroheker, T., Chagnon, M. C., Pinnert, M. F., Berges, R. and
Canivenc-Lavier, M. C. 2003. Estrogenic effects of food wrap packaging xenoestrogens and flavonoids in female Wistar rats: a comparative study. Reprod. Toxicol. 17: 421-432.

29. Sweeney, T. 2002. Is exposure to endocrine disrupting compounds during fetal/post-natal development affecting the reproductive potential of farm animals? Domest. Anim. Endocrinol. 23: 203-209.

30. Thigpen, J. E., Setchell, K. D., Ahlmark, K. B., Locklear, J., Spahr, T., Caviness, G. F., Goelz, M. F., Haseman, J. K., Newbold, R. R. and Forsythe, D. B. 1999. Phytoestrogen content of purified, open- and closed-formula laboratory animal diets. Lab. Anim. Sci. 49: 530-536.

31. Toyoda, Y. and Chang, M. C. 1974. Fertilization of rat eggs in vitro by epididymal spermatozoa and the development of eggs following transfer. J. Reprod. Fertil. 36: 9-22.

32. Whitten, P. L. and Patisaul, H. B. 2001. Cross-species and interassay comparisons of phytoestrogen action. Environ. Health Perspect. 109: $5 \mathrm{~s}-20 \mathrm{~s}$.

33. Wisniewski, A. B., Klein, S. L., Lakshmanan, Y. and Gearhart, J. P. 2003. Exposure to genistein during gestation and lactation demasculinizes the reproductive system in rats. J. Urol. 169: 1582-1586.

34. Yanagimachi, R. 1994. Mammalian fertilization. pp. 189-317. In: The Physiology of Reproduction. (Knobil, E. and Neil, J. D. eds.), New York: Raven Press; 1994.

35. Yu, W. J., Lee, B. J., Nam, S. Y., Kim, Y. C., Lee, Y. S. and Yun, Y. W. 2003. Spermatogenetic disorders in adult rats exposed to tributyltin chloride during puberty. J. Vet. Med. Sci. 65: 1331-1335. 